\title{
TRATAMENTOS FÍSICOS E QUÍMICOS NA EMERGÊNCIA E NO CRESCIMENTO DE PLÂNTULAS DE PINHEIRA ${ }^{(1)}$
}

\author{
SILVIA NIETSCHE ${ }^{(2)}$; MARLON CRISTIAN TOLEDO PEREIRA ${ }^{(2)}$; CLAUDINÉIA FERREIRA NUNES ${ }^{(3)}$; LIZE DE \\ MORAES VIEIRA DA CUNHA ${ }^{(3)}$; VALDEIR DIAS GONÇALVES ${ }^{(3)}$; WAGNER FERREIRA DA MOTA (2); \\ FERNANDO ALMEIDA SANTOS ${ }^{(3)}$
}

\begin{abstract}
RESUMO
O objetivo do presente trabalho foi verificar o efeito do armazenamento e a influência de tratamentos físicos e químicos sobre a emergência e o crescimento de plântulas de pinheira. Frutos de pinheiras foram coletados em um pomar comercial no município de Nova Porteirinha, Minas Gerais. Os frutos colhidos maduros foram despolpados e suas sementes, lavadas em água corrente. O delineamento utilizado foi o de blocos casualizados, em um esquema fatorial, com cinco tratamentos (testemunha, imersão em vinagre, escarificação com lixa, escarificação em liquidificador e desponte com alicate) e quatro épocas de armazenamento em geladeira (0,2, 4 e 6 meses). Trinta dias após o plantio de cada época, foi avaliada a porcentagem de plântulas emergidas, tempo médio para emergência, número de folhas, diâmetro, altura das plantas, matéria fresca e matéria seca da parte aérea e do sistema radicular. Dentre os principais resultados pode-se destacar que não foram observados efeitos significativos dos tratamentos na quebra de dormência das sementes de pinheira e o armazenamento em geladeira por seis meses não prejudicou a emergência e o desenvolvimento das plântulas de pinheira.
\end{abstract}

Palavras-chave: Annona squamosa, dormência, sementes.

\section{ABSTRACT \\ PHYSICAL AND CHEMICAL TREATMENTS ON EMERGENCY AND GROWTH OF SWEETSOP PLANTLETS}

This study aimed verifying the effect of the storage and the influence of physical and chemical treatments on emergency and growth of sweetsop plantlets. Sweetsop fruits were collected in a commercial orchard in Nova Porteirinha District, Minas Gerais. Fruits were picked when ripe, the pulp was extracted and the seeds washed. The design was in blocks at random, in a factorial system with five treatments (control, immersion in vinegar, sandpaper scarification, scarification in blender and cutting with pliers) and four periods of storage at $4{ }^{\circ} \mathrm{C}(0,2,4$ e 6 months). Percentage of surfaced plantlets, average time to

( $\left.{ }^{1}\right)$ Recebido para publicação em 2 de junho de 2004 e aceito em 5 de maio de 2005.

$\left({ }^{2}\right)$ Departamento de Ciências Agrárias, Campus de Janaúba, UNIMONTES, Caixa Postal 91, 3944-0000 Janaúba, MG. E-mail: silvia.nietsche@unimontes.br

$\left({ }^{3}\right)$ Estudantes do Curso de Agronomia, UNIMONTES, Janaúba, MG. 
emergency, number of leaves, diameter, plant height, shoot root fresh and dry matter were evaluated thirty days after the planting of each period. Among the main results we could pointout that no significative effects of the treatments on breaking sweetsop seeds dormancy were observed and also the storage at low temperatures up to six months did not damage emergency and growth of sweetsop plantlets.

Key words: Annona squamosa, dormancy, seeds.

\section{Introdução}

O cultivo de anónaceas, principalmente a pinheira (Annona squamosa L.) vem experimentando considerável crescimento no Sudeste e Nordeste brasileiro, notadamente nos perímetros irrigados, pela possibilidade de se conseguir mais de uma safra por ano e devido aos bons preços obtidos pelas frutas nos principais mercados consumidores do País (ArAújo, 1999). No Brasil, a área cultivada com pinha atinge atualmente 6.625 há, sendo a Região Nordeste responsável por $93,23 \%$ desse total. O principal produtor nacional é o Estado da Bahia, seguido de Pernambuco e Alagoas (IBGE, 2002). Atualmente, propaga-se a pinheira, quase exclusivamente, via sementes, daí a grande variabilidade de plantas e frutos encontrada nos pomares comerciais. A maioria dos produtores ainda não utiliza as mudas enxertadas de pinha por desconhecer cultivares selecionadas, precocidade na produção e os portaenxertos mais adequados para as condições edafoclimáticas locais e, sobretudo, em função de as mudas de pé franco apresentarem menor custo e serem de mais fácil aquisição (Kavati, 1997; Menezes et al., 2002).

De acordo com Simão (1971), citado por PINTO (1975), as sementes de muitas espécies frutíferas, principalmente daquelas originárias de frutos carnosos, germinam tão logo sejam colocadas em condições favoráveis de solo e ambientes, porém outras, nas mesmas condições edafoclimáticas não germinam. Essa dormência pode ser causada por um impedimento físico, que dificulta a embebição da semente e a oxigenação do embrião, que permanece latente (LEMOS et al., 1987). GARNER e CHAUDHRI (1976), recomendam que as sementes de anonáceas sejam colocadas em água durante 24 horas e semeadas logo em seguida a uma profundidade de $2 \mathrm{~cm}$.

O objetivo deste trabalho foi verificar o efeito do armazenamento e a influência de tratamentos físicos e químicos sobre a emergência e o crescimento de plântulas de pinheira.

Frutos de pinheiras foram coletados em um pomar comercial no município de Nova Porteirinha, na safra de novembro a fevereiro de 2001-2002. O delineamento experimental utilizado foi o de blocos casualizados, em um esquema fatorial, tendo cinco tratamentos caracterizados pelos métodos de quebra de dormência, quatro épocas de armazenamento em geladeira, com quatro repetições. Cada parcela constituiu-se de 20 sementes. Após serem selecionadas, as sementes foram acondicionadas em sacos de papel e armazenadas na geladeira a $7{ }^{\circ} \mathrm{C}$. As sementes da primeira época de armazenamento (mês zero) foram submetidas aos seguintes tratamentos: imersão em vinagre por 15 minutos; escarificação em liquidificador doméstico (400 rpm) por 10 segundos intermitentes; escarificação com lixa número 80, sendo agitadas dentro de uma lata de boca larga onde partes internas da mesma foram recobertas pela lixa, por 10 minutos ininterruptos e, finalmente, o desponte do tegumento foi feito com um alicate. A semeadura das quatro épocas foi realizada nas seguintes datas: 14/3/2002, 14/5/2002, 14/7/2002 e 14/9/2002, e a emergência, controlada diariamente até o 30.o dia após a semeadura, para fins de cálculo do índice de velocidade de germinação, sendo utilizada a fórmula sugerida por MAGUIRE (1962):

$$
\operatorname{IVE}=\mathrm{E}_{1} / \mathrm{N}_{1}+\mathrm{E}_{2} / \mathrm{N}_{2}+\ldots+\mathrm{E}_{\mathrm{n}} / \mathrm{N}_{\mathrm{n}}
$$

O levantamento da porcentagem de germinação foi efetuado em média com 33 dias após o plantio, para as quatro épocas testadas. O tempo médio de emergência das plântulas foi estimado segundo EDMOND e Drapala (1958), pela equação:

$$
T m=\frac{G_{1} T_{1}+G_{2} T_{2}+\ldots G_{n} T_{n}}{G_{1}+G_{2}+\ldots G_{n}}
$$

Trinta dias após o plantio de cada época, avaliou-se a porcentagem de plântulas emergidas, computando-se as sementes que deram origem a uma plântula normal. A avaliação do número de folhas, diâmetro e altura das plantas foi realizada sessenta dias após o plantio para cada época, e determinada a matéria fresca da raiz e da parte aérea, conforme recomendações de BRASIL (1992). As características avaliadas foram submetidas à análise de variância, sendo testadas e ajustadas às equações de regressão para todas as características avaliadas. 
Com os resultados obtidos, observou-se que, para os diferentes tratamentos, não ocorreram efeitos significativos para nenhuma das variáveis avaliadas. O coeficiente médio de variação para as características avaliadas foi de $21,26 \%$. Entretanto, em estudos realizados por Lemos et al. (1987), constatou-se que a escarificação física feita com lixa por dez minutos, foi significativamente superior quanto à percentagem $\mathrm{e}$ à velocidade de emergência das sementes de pinha. LEDO e CABANELAS (1997), trabalhando com sementes de graviola, verificaram que o melhor tratamento foi a escarificação das sementes em liquidificador por cinco segundos; para a pinha e atemóia, com o uso do ácido giberélico, observaram aumentos significativos na emergência e velocidade de germinação (FERREIRA et al., 2002; STENZEL et al., 2003). Embora pertençam à mesma família, até o momento não foi relatado um método que atue de forma eficiente na quebra de dormência de pinha e atemóia.

Pinto e Genu (1984) relatam a possibilidade de haver uma dormência endógena nas sementes de anonáceas, mas resultados contraditórios ainda deixam dúvidas aos pesquisadores. Em relação às características de número de folhas, altura de plantas, massa fresca e seca da parte aérea, foram observados valores superiores em plântulas provenientes de sementes armazenadas durante seis meses (Figura 1). Verificou-se no número de folhas e altura comportamento quadrático ao longo do armazenamento, com leve redução e estabilização até os dois meses respectivamente. Posteriormente, houve aumento até o fim do período de armazenamento, quando foram obtidas médias superiores a 11 folhas por planta e altura superior a $16 \mathrm{~cm}$ respectivamente. FERREIRA et al. (1997), ao trabalharem com pinha e atemóia, verificaram que em sementes de tais espécies não houve impedimentos físicos à entrada de água, descartando a possibilidade de a dormência ocorrer em função da dureza do tegumento, mas sim, de estar associada ao mecanismo de dormência que relaciona como sobrevivência estacional, identificado em Annona diversifolia por EsQuinca et al. (1997). Portanto, os resultados verificados no presente trabalho podem estar associados ao evento da dormência estacional já observado em outra espécie da família Anonaceae. Estudos posteriores, porém, devem ser realizados para confirmar as observações iniciais.

Pode-se observar que comportamento similar em relação à porcentagem de emergência, destacando que, mesmo após 180 dias de armazenamento em geladeira, foram obtidos valores superiores a $70 \%$ de plântulas emergidas. Os valores obtidos em relação à porcentagem de emergência no presente trabalho são confirmados por STENZEL et al (2003) que, ao estudar superação de dormência em sementes de pinheira, obtiveram médias de $75 \%$ de plântulas emergidas.
Para os viveiristas, essa é uma informação muito valiosa, pois além de garantir o armazenamento de sementes de pinha por, pelo menos, seis meses, vai permitir realizar um cronograma de atividades no viveiro ao longo do ano, sempre disponibilizando mudas de pinheira para os produtores.

Observou-se, de maneira geral, que os piores resultados foram obtidos aos dois meses de armazenamento, para todas as características avaliadas. Dentre as características, destacam-se o baixo crescimento e desenvolvimento da parte aérea e do sistema radicular, verificados em análises, com redução até o segundo e o terceiro mês respectivamente, com posterior elevação até o fim do período de armazenamento (Figura 1). Para PINTo e GENU (1984), esse fator pode estar associado à própria dormência endógena da semente, que poderia estar inibindo o desenvolvimento das plântulas. De acordo com TAIZ e Zeiger (1991), em sementes de cereais, o desenvolvimento das plântulas está associado às giberelinas. Esse hormônio ativa a síntese de enzimas que vão hidrolisar as reservas da semente, liberando energia para o crescimento do embrião. Além disso, esse regulador de crescimento eleva o alongamento celular, fazendo com que a radícula e a parte aérea possam desenvolver (SAlisbury e Ross, 1992). Apesar destes estudos terem sido realizados em cereais, STENZEL et al. (2003), trabalhando com o uso do ácido giberélico em híbridos de atemóia, identificaram aumentos significativos na velocidade de emergência e no crescimento das plântulas. Com relação ao índice de velocidade de emergência (I.V.E) (Figura 2), observou-se para época zero uma velocidade de 1,67 semente emergida por dia, diferindo significativamente das demais épocas, pois houve redução do IVE até os dois meses, elevando posteriormente até o fim do armazenamento. Em trabalhos realizados com sementes de graviola, determinou-se um I.V.E de 0,91 semente/dia, em condições de escarificação em liquidificador por cinco segundos, demonstrando menor velocidade de emergência para a graviola, quando comparada às sementes de pinha (Ledo e CABANELAS, 1997)

Observou-se no tempo médio de germinação, avaliado nos quatro períodos, uma oscilação de oito dias entre as quatro épocas avaliadas, sendo o menor valor encontrado na época zero, em média, de 16 dias para emergir (Figura 2). Com a ampliação do período de armazenagem, houve aumento desse tempo, quando aos quatro meses foi observado o maior tempo médio de germinação, com posterior declínio aos seis meses. Quando se comparam tais resultados com outras espécies como a pitanga, com tempo médio de 23 dias para emergir, destacam-se as sementes de pinheira, nas condições norte-mineiras, com menor tempo para emergir (SCALON et al., 2001). 

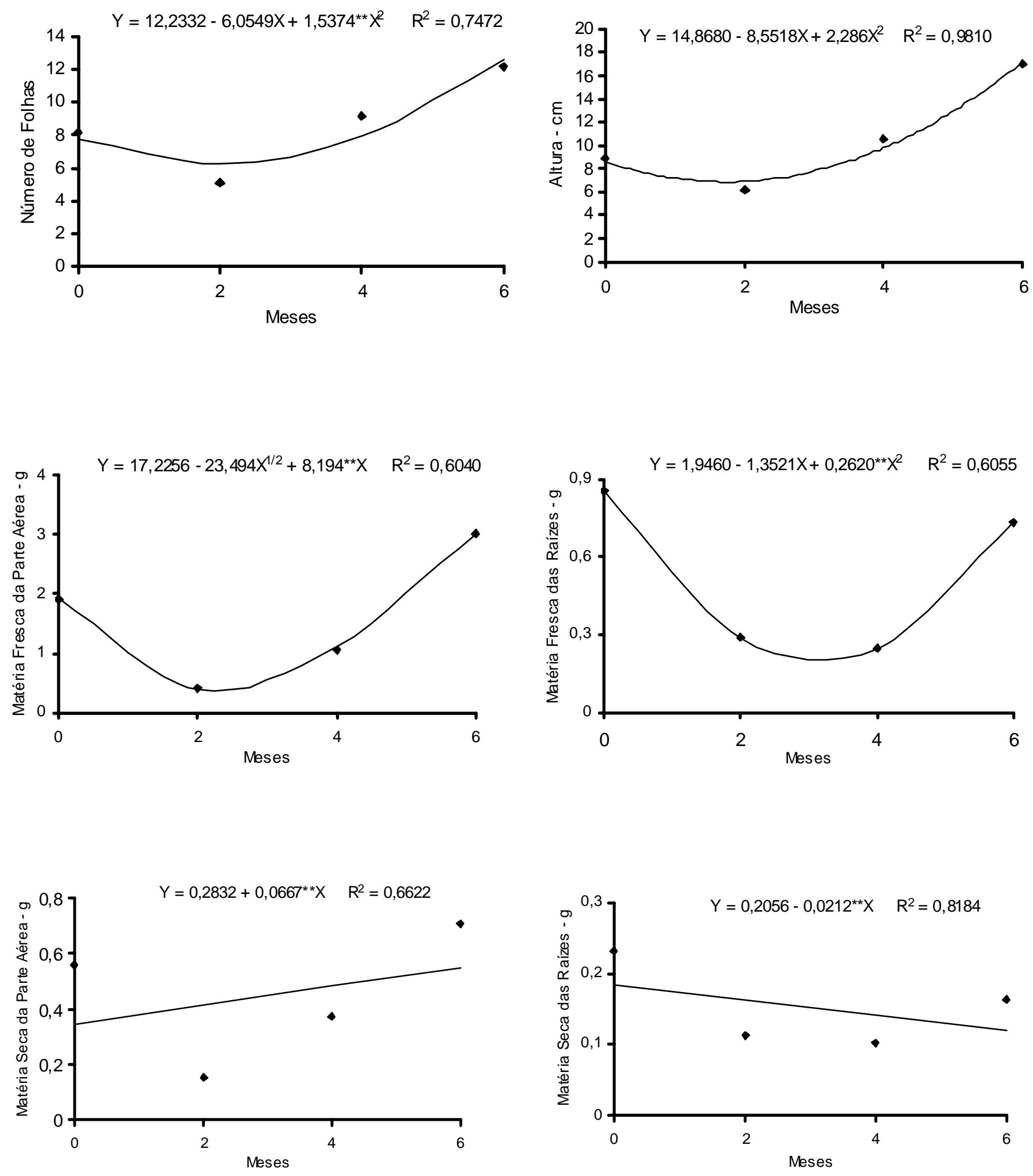

Figura 1. Número de folhas, altura, massa fresca da parte aérea e da raiz e massa seca da parte aérea e da raiz, em plântulas de pinheira, Janaúba, Norte de Minas Gerais, 2002. 

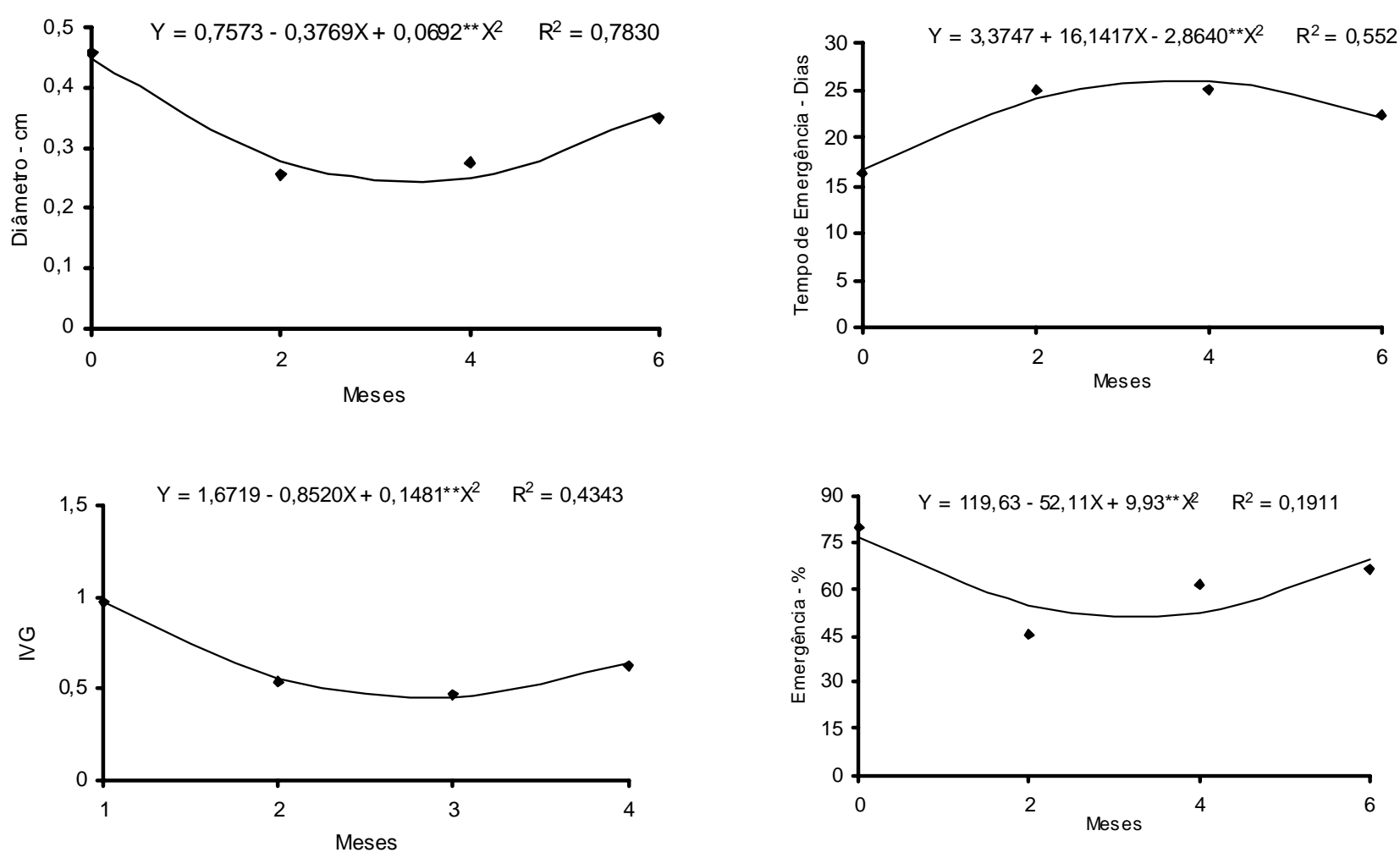

Figura 2. Diâmetro do caule, tempo médio de emergência, IVE e \% de emergência em plântulas de pinheira, Janaúba, Norte de Minas Gerais, 2002.

Apesar do crescente interesse econômico e social nas espécies da família Anonaceae, há ainda uma grande carência em pesquisas sobre estas espécies, principalmente, trabalhos relacionados ao crescimento e desenvolvimento em ecossistemas específicos, como é o caso do Norte de Minas Gerais.

\section{Agradecimentos}

Os autores agradecem à Fundação de Amparo a Pesquisa do Estado de Minas Gerais - FAPEMIG, pela concessão da bolsa e ao Sr. Edson de Souza Martins, pelo apoio na realização deste trabalho.

\section{REFERÊNCIAS}

ARAÚJO,J.F.; ARAÚJO, J.F.; ALVES, A.A.C. Instruções técnicas para o cultivo da pinha (Annona squamosa L.). Salvador: EBDA, 1999. 44p. (EBDA. Circular Técnica, 7).

BRASIL. Ministério da Agricultura e Reforma Agrária. Regras para análise de sementes. Brasília, 1992.
EDMOND, J.B.; DRAPALA, W.J. The efffects of temperature, sand and soil, and acetone on germination of okra seed. Proceedings of the American Society for Horticultural Science, Leuven, v.71, p.428-434. 1958.

FERREIRA, G.; CEREDA, E.; SILVA, C.P.; CUNHA, R.J.P. ; CAETANO, A. Inhibition study of sugar apple (Annona squamosa $\mathrm{L}$ ) and atemoya (Annona squamosa x Annona cherimola) seeds. In: CONGRESSO INTERNACIONAL DE ANONACEAS, 1., 1997, Chapingo, México. Memórias... Chapingo, México: Universidad Autonoma Chapingo, 1997. p.210-224.

FERREIRA, G.; ERIG, P.R. ; MORO, E. Uso de ácido giberélico em sementes de fruta-do-conde (Annona squamosa $\mathrm{L}$ ) visando à produção de mudas em diferentes embalagens. Revista Brasileira de Fruticultura, Jaboticabal, v.24, n.1, p.178-182, 2002.

GARNER, R.J.; CHAUDHRI, S.A. Annona muricata: soursop, ecology and growth in relation to propagation of tropical fruits trees. Slough: CAB, 1976. p.233-235.

ESQUINCA, A.G.; MOCTEZUMA, J.G.A. ; PÉREZ, G.M.P. Duracion de la latência e importância de la cubierta dura y de la inmadurez anatomica, en la inhibición de la germinación de la papausa blanca (Annona diversifolia Saff., Magnoliade, Annonaceae). Investigación, ciencias y artes en Chiapas, México, v.23, p.37-44, 1997. 
IBGE. Levantamento Sistemático da Produção Agrícola. Disponível em: www.sidra.ibge.gov.br/sidra/agro/ agro.htm>. Acesso em julho de 2002.

KAVATI, R.; PIZA JÚNIOR, C.T. Formação e manejo do pomar de fruta-do-conde, atemóia e cherimóia. In: SÃO JOSÉ, A.R.; SOUZA, I.V.B.; MORAIS, O.M.; REBOUÇAS, T.N.H. (Ed.). Anonáceas: produção e mercado (pinha, graviola, atemóia e cherimóia). Vitória da Conquista: UESB-DFZ, p.75-83. 1997.

LEDO, A. S.; CABANELAS, C.I.L. Superação de dormência de sementes de graviola (Annona muricata L.). Revista Brasileira de Fruticultura, Cruz das Almas, v.19, p.397-400. 1997.

LEMOS, E. E. P.; CAVALCANTE, R.L.R.R.; CARRAZONE, A. A.; LOBO, T. M. L. Germinação de sementes de pinha submetidas a tratamentos para quebra de dormência. In: CONGRESSO BRASILEIRO DE FRUTICULTURA, 9., 1987, Campinas. Anais... Campinas: SBF/CBF, 1987. v.2. p. 675-678.

MAGUIRE, J.D. Speeds of germination-aid selection and evaluation for seedling emergence and vigor. Crop Science, Madison, v.2, p.176-177, 1962.

MENEZES, L. S.; CARDOSO, E. de A.; PIRES, G. de S.; AMARO FILHO, J. Efeito de substrato na produção de mudas de pinheira (Annona squamosa L.) em bandejas de isopor. In: CONGRESSO BRASILEIRO DE FRUTICULTURA, 17., 2002, Belém. Anais... Belém: SBF/CBF, 2002. (Cd-Rom)
PINTO, A.C.Q. Influência de hormônios sobre o poder germinativo de sementes de graviola (Annona muricata L.). In: CONGRESSO BRASILEIRO DE FRUTICULTURA, 3., 1975, Rio de Janeiro. Anais... Rio de Janeiro: SBF/CBF, 1975. v.2. p. 415-421.

PINTO, A. Q.; GENU, P.J. C. Contribuição ao estado técnicocientífico da graviola (Annona muricata L.). In: CONGRESSO BRASILEIRO DE FRUTICULTURA, 7., 1984, Florianópolis, SC. Anais... Florianópolis: SBF, 1984. v.2, p.529-546.

SALISBURY, F.B.; ROSS, C.W. Plant Physiology. 4 ed. California: Wadsworth, 1992, 682 p.

SCALON, S de P.Q.; FILHO SCALON, H.; RIGONI, M.R.; VERALDO, F. Germinação e crescimento de mudas de pitangueira (Eugenia uniflora L.) sob condições de sombreamento. Revista Brasileira de Fruticultura, Jaboticabal, v.23, n. 3, p.652-655. 2001.

SIMÃO, S. Anoneira. In: Manual de Fruticultura. São Paulo, Ceres. 1971, p.469-476.

STENZEL, N.M.C.; MURATA, I.M.; NEVES, C.S.V.J. Superação de dormência em sementes de atemóia e fruta-do-conde. Revista Brasileira de Fruticultura, Jaboticabal, v.25, n. 2, p.305308, 2003.

TAIZ, L.; ZEIGER, E. Plant Physiology. California: Benjamin Cummings Publishing, 1991. p. 565. 